\title{
Effect of gut contents and lipid degradation on condition measures in larval fish
}

\author{
Steve E. Lochmann ${ }^{1, *}$, Gary L. Maillet ${ }^{1}$, Christopher T. Taggart ${ }^{1}$, Kenneth T. Frank ${ }^{2}$ \\ 'Department of Oceanography, Dalhousie University, Halifax, Nova Scotia, Canada B3H 4J1 \\ ${ }^{2}$ Marine Fish Division, Department of Fisheries and Oceans, Bedford Institute of Oceanography, PO Box 1006, Dartmouth, \\ Nova Scotia, Canada B2Y 4 A2
}

\begin{abstract}
The importance of gut contents to estimates of lipid class composition was evaluated by comparing the lipid composition of gut contents and larval Atlantic cod Gadus morhua body tissue analyzed separately. Ingested prey accounted for an average of $56 \%$ (range $=4$ to $95 \%$ ) of the total lipids from individual larvae. Energy reserves and structural lipids were both influenced by contributions from gut contents. Lipids from prey in the gut biased condition indices based on lipid class composition (triacylglycerol to sterols ratio and triacylglycerol content). A review of studies in the literature, where biochemical measures of condition were assessed, determined that $75 \%$ of studies on condition may be biased by prey in the guts. We further investigated the effects of collection and handling protocol on lipid class composition of cod larvae. Tracylglycerol. phospholipids and free fatty acids increased significantly during a sımulated collection process. We also examined the effect of time delays between death and preservation on lipid composition. Concentration of free fatty acids, mono- and diacylglycerol increased and triacylglycerol and phospholipids decreased with increasing time between death and preservation. However, the time trend explained only a small portion (2 to $32 \%$ ) of the overall variability. We suggest studies employing other biochemical measures of condition may also suffer from the vanability we identified as being introduced by collection and processing protocols.
\end{abstract}

KEY WORDS: Marine larvae - Condition indices - Lipid composition - Degradation - Biochemical measures - Gut contents - Iatroscan TLC-FID - Atlantic cod

\section{INTRODUCTION}

A variety of biochemical measures have been employed to characterize the physiological condition of early life stages of marine fish (Ferron \& Leggett 1994 and references therein) and aquatic invertebrates (Gallager et al. 1986, Hakanson 1987, Ouellet et al. 1992). These measures are used to detect changes in the biochemical state occurring at the cellular level by quantifying chemical constituents that act as energy substrates, reserves, and physiological rate indicators. The biochemical measures of condition that have been developed for larval fish include nucleic acid content, principally the ratio of RNA to DNA (Bulow 1970,

- Present address; Fisheries Biology Program, University of Arkansas at Pine Bluff, Box 4990, 1200 North University Drive, Pine Bluff, Arkansas 71611, USA

E-mail: lochmann_s@vx4500.uapb.edu
Buckley 1979, 1984, Clemmesen 1987), protein content (Buckley 1980), enzyme activity (Hjelmeland et al. 1984, Ueberschär 1988, Clarke et al, 1992), and lipid content (Fraser 1989, Hakanson 1993, Lochmann et al. 1995)

The main source of variation evaluated in studies investigating biochemical measures of condition is food availability. However, biochemical composition can be influenced by factors other than food availability. The additional sources of variability [e.g. maternal influences, diel variations, toxicant levels; see Ferron \& Leggett (1994) for detailed examples] have been noted as potentially important, but few have been evaluated.

The objective of our study was to evaluate the factors related to sample processing protocols and lipid-based measures of condition. One factor which can affect biochemical measures is whether or not gut contents are removed prior to analyses. In our study, the contribu- 
tion of lipids from prey items in guts to overall lipid composition was evaluated by separately analyzing lipids from larval Atlantic cod Gadus morhua and their gut contents. We put our study in perspective by evaluating published results from a recent review of condition measures for marine fish larvae (Ferron \& Leggett 1994) to determine what steps were taken in other studies to account for prey in the guts.

A second factor which can affect biochemical measures is the collection protocol, which influences the likelihood that samples will undergo degradation. If too much time elapses or temperatures are too high, the biochemical measures may be biased due to alteration of the biochemical constituents. For example, the occurrence of free fatty acids, mono- and diacylglycerol in larval fish has been suggested to result from degradation of more complex lipid classes (triacylglycerol and phospholipids) and, therefore, provide a measure of sample quality (Christie 1973, Sasaki \& Capuzzo 1984, Fraser 1989). Furthermore, lipid classes which degrade at different rates may confound the use of ratios such as the triacylglycerol to sterols index of condition (Fraser 1989, Hakanson 1989). Here we examine the effect of collection and time delays between death and preservation on lipid class composition in larval cod.

\section{MATERIALS AND METHODS}

Influence of gut contents. To evaluate the influence of prey in the guts on the lipid composition of individual larval cod, the quantity of different lipid classes in ingested prey was compared to the quantity in the body of the larvae from which the gut and contents had been removed. The method employed for removal of gut contents consisted of gently teasing the gut away from the body with the use of a dissecting needle. The lipid composition of whole-body tissue and the gut were analyzed separately for 20 cod larvae collected on the eastern Scotian Shelf (Canada) in January 1992 (Ocean Production Enhancement Network Cruise 92-18; Griffin \& Anderson 1993).

Lipid degradation. Fertilized Atlantic cod eggs were obtained from the Ocean Sciences Centre at Memorial University, St. Johns, Newfoundland, Canada. Larvae were offered rotifers Brachious sp. at 1 to $2 \mathrm{ml}^{-1}$ from the day of hatching. Forty $8 \mathrm{~d}$ post-modal-hatch-date larvae were collected live, immediately placed in cryovials, and stored in liquid nitrogen. To simulate a typical field sampling protocol where nets are towed for extended periods prior to sample preservation, the remaining larvae (approximately 750) were put into a $250 \mu \mathrm{m}$ mesh container. The container was placed in $3^{\circ} \mathrm{C}$ flowing seawater and agitated for $20 \mathrm{~min}$. Larvae were impinged against the mesh, but were not extruded through it. The treatment killed the larvae without visibly damaging external tissues. Death was verified by examination of the heart under a dissecting microscope. Forty of these larvae were immediately placed in cryovials and preserved in liquid nitrogen. From the remaining larvae, equal numbers of dead larvae were transferred to water baths at temperatures of $2.5 \pm 0.06($ mean $\pm \mathrm{SD}), 5.4 \pm 0.08,9.9 \pm 0.22,14.8 \pm$ 0.05 , and $21.4^{\circ} \mathrm{C} \pm 0.58$. Approximately 30 larvae were sampled from each water bath at $15,60,120$, and $180 \mathrm{~min}$ after removal from the mesh container, placed in cryovials, and preserved in liquid nitrogen. These treatments were designed to mimic the protocol and time course expected when sampling, sorting, and preserving larval cod in the field.

Lipid class determination. All larvae for both aspects of this study were analyzed individually and the guts were removed prior to lipid extraction. Larvae were placed into $1 \mathrm{ml}$ of dichloromethane-methanol solvents (2:1 v/v, HPLC grade) and lipids were extracted for approximately $24 \mathrm{~h}$. Five $\mu \mathrm{g}$ of nonadecane (internal standard) were added to each sample to estimate sample recovery. Samples were maintained on ice prior to evaporation under purified nitrogen gas and reconstituted twice in $10 \mathrm{ml}$ of extraction solvent. Lipid class measurements were made using a ChromarodIatroscan Mark V TLC/FID (thin-layer chromatography-flame ionization detection) Analyzer (IATRON Lab., Inc., Tokyo, Japan) (Ackman et al. 1990). The flame ionization detector was operated at a hydrogen flow rate of $160 \mathrm{ml} \mathrm{min}{ }^{-1}$ and an air flow rate of $2000 \mathrm{ml}$ $\mathrm{min}^{-1}$ The S-III Chromarods (IATRON) were calibrated using synthetic standards (SIGMA) and the standards were weighed to the nearest $0.1 \mu \mathrm{g}$.

The lipid classes (abbreviations and synthetic standards) examined were sterol esters (STE, cholesteryl palmitate), triacylglycerol (TAG, tripalmitin), free fatty acids (FFA, palmitic acid), diacylglycerol (DAG, dipalmitin), sterols (ST, cholesterol), monoacylglycerols (MAG, 1-monopalmitoyl-rac-glycerol), and polar or phospholipids (PL, L-a-phosphatidylcholine). Standards were dissolved in solvents identical to those used for larval samples and were used immediately. Larvae were dried at $60^{\circ} \mathrm{C}$ to constant weight after lipid extraction. The resultant defatted dry weight (DDW) of individual larvae was estimated to the nearest $0.1 \mu \mathrm{g}$ with a Cahn Gram Electrobalance (model G, Ventron Corp., Paramount, CA, USA). A more detailed description of the Iatroscan lipid protocol can be found in Lochmann et al. (1995).

Lipid and DDW data were not distributed normally and were improved by a $\log _{10}$ transformation. As the lipid data were not completely normalized by this transformation, we also rank transformed the data. We 
initially compared the lipid class composition of larvae collected live to those which underwent the simulated sampling protocol using analyses of covariance. Transformed DDW was required as a covariate because our data show lipid content is size-dependent, consistent with Shearer (1994). Our analyses were based on both the $\log _{10}$ and the rank transformed data. Time trends in lipid class composition were assessed by regressing each lipid class against time for each temperature treatment. We included transformed DDW data in the regressions to account for larval size differences among the time-delay treatments.

\section{RESULTS \\ Influence of gut contents}

Examination of lipid classes in the body tissue of cod larvae and in the gut indicated that prey can contribute significantly to the lipid composition of a larva with prey in the gut. The total dry weight (DDW + lipids from gut contents + lipids from larval tissue) ranged from 0.3 to $72.8 \mathrm{mg}$ (Fig. 1a) for the 20 larvae from which guts and body tissue were analysed separately. The relative contribution of lipids from gut contents to total lipids (lipids from gut contents + lipids from larval tissue) varied widely among larvae (Fig. 1b). The energy reserve, TAG, varied from near zero to more than $250 \mu \mathrm{g}$, and the contribution of the gut and contents to TAG concentration averaged $53 \%$ (range $=4$ to $98 \%$; Fig. 1c, d). The structural lipid classes (ST and PL) generally correlated with size, but the contribution from the gut and contents averaged $53 \%$ (range $=4$ to $96 \%$ ) for ST and $56 \%$ (range $=3$ to $95 \%$ ) for PL (Fig. 1e-h). In general, the contribution of lipids from the gut and contents to total lipids did not vary systematically with larval size. Note that data for 9 larvae, covering the full size range of all 20 larvae, are presented graphically in Fig. 1.

These results led us to review the methods used by other investigators to account for what appears to be a significant gut-related influence on the biochemical condition of fish larvae. We evaluated 60 of 280 references listed in a recent review of condition measures in marine fish larvae (Ferron \& Leggett 1994). These 60 papers were representative of
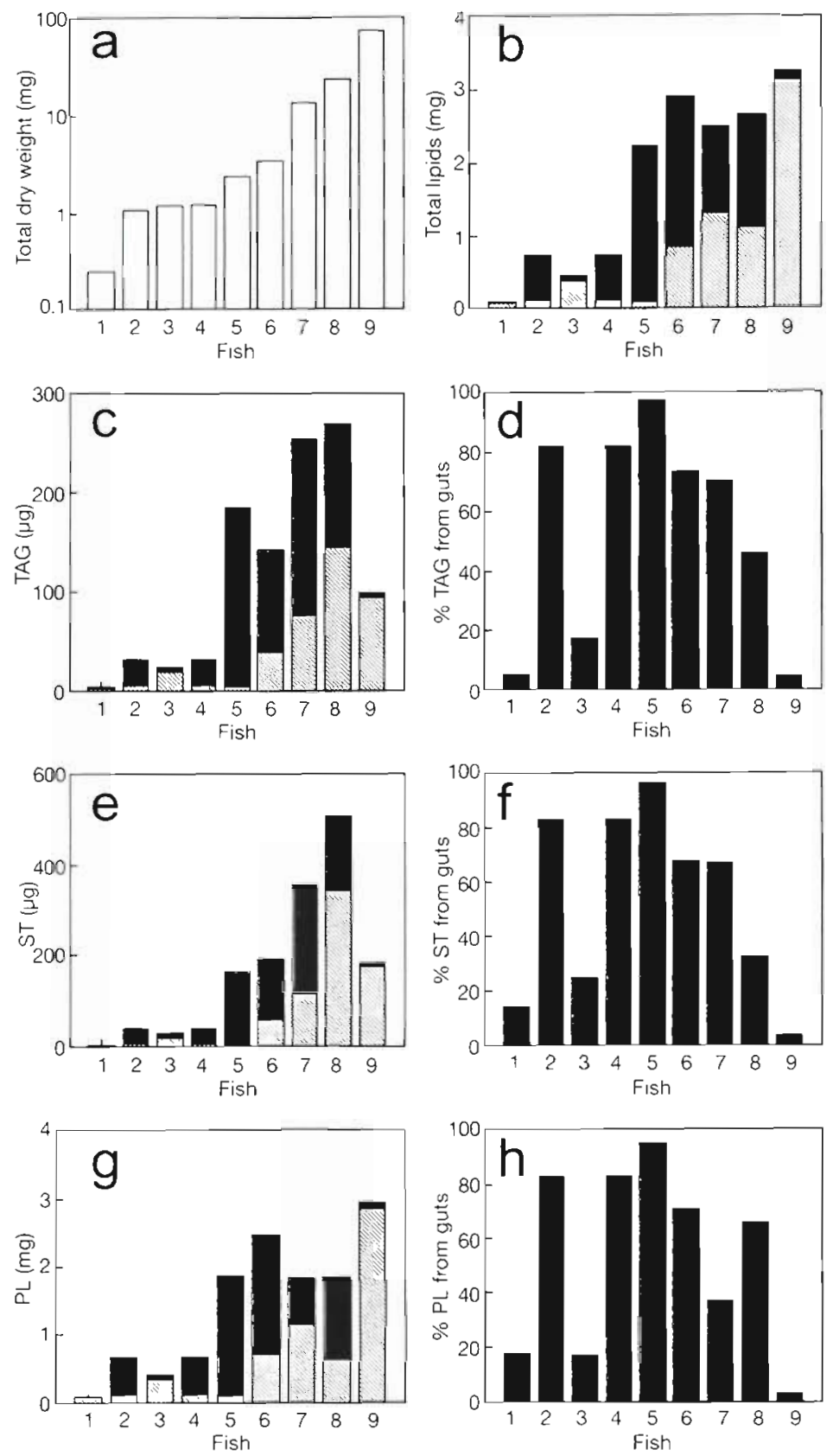

Fig. 1. (a) Total dry weight (defatted dry wenght + lipids from gut contents + lipids from larval tissue); (b) total lupids; (c) triacylglycerol (TAG); (d) percentage of TAG from gut contents; (e) sterols (ST); (f) percentage of ST from gut contents; (g) phospholipids (PL); (h) percentage PL from gut contents of 9 (fish 1 to 9) cod larvae. Gut contents (solid bars) and larval tissue (cross-hatched bars) were analysed separately for lipid class composition. These 9 larvae are a representative subset of 20 larvae processed in an identical manner (see text)

studies using biochemical measures that included nucleic acids, lipids, amino acids, enzymes, and carbon, hydrogen, and nitrogen analyses to assess condition. The results indicated that only a small fraction $(25 \%)$ of studies addressed gut contents in one way or. 
another, while the majority of studies (75\%) made no reference to gut clearance or removal prior to biochemical analyses (Table 1).

\section{Lipid degradation}

We investigated the potential for lipids to degrade or alter during the collection process and after death in cod larvae exposed to different temperatures and time intervals between death and preservation. The lengths of larvae were not measured, but average DDW ranged from 21.1 to $27.4 \mu$ larva $^{-1}$ (Table 2). Live larvae were smaller than larvae taken randomly from the $250 \mu \mathrm{m}$ mesh container after agitation (ANOVA, p = $0.005)$. Random draws within temperature treatments also resulted in samples with different average DDW (see especially $5^{\circ} \mathrm{C} / 35 \mathrm{~min}$ time delay, Table 2 ). Phospholipids ranged from 3.48 to $10.32 \mu$ larva $^{-1}$. Sterols were more uniform than PL through time at all temperatures and ranged from 0.74 to $1.07 \mu \mathrm{glarva}^{-1}$ Triacylglycerols were more variable than ST through time, especially at 5,15 , and $21^{\circ} \mathrm{C}$ and ranged from 0.03 to $0.21 \mu \mathrm{g} \mathrm{larva}^{-1}$. Di- and monoacylglycerols ranged from zero to 0.18 and $0.16 \mu \mathrm{g}$ larva ${ }^{-1}$, respectively. Free fatty acids increased with time at most temperatures and ranged from 0.04 to $0.93 \mu \mathrm{g}$ larva $^{-1}$

Table 1. Classification of studies addressing the potential bias of prey items in the guts of larval fish as determined from references in a review of condition medsures for marine fish larvae by Ferron \& Leggett (1994). Sixty of the 280 studies used biochemical measures (nucleic acids, lipids, amino acids, enzymes, and carbon, hydrogen, and nitrogen analyses) to assess condition

\begin{tabular}{|lc|}
\hline $\begin{array}{l}\text { Classification of measures taken } \\
\text { to address prey in larval guts }\end{array}$ & $\begin{array}{c}\text { No. of } \\
\text { studies }\end{array}$ \\
\hline $\begin{array}{l}\text { No reference to gut clearance or gut removal } \\
\text { Specifically stated guts were removed }\end{array}$ & 45 \\
$\begin{array}{l}\text { Specifically stated guts were neither cleared } \\
\text { nor removed }\end{array}$ & 1 \\
No feeding permitted (complete starvation) & 4 \\
Starvation periods used to clear guts & 5 \\
Used diel feeding periodicities to minimize & 2 \\
$\quad$ gut fullness & 60 \\
Total & \\
aSeventy-five percent of these published studies may have \\
a gut-related bias in biochemically based condition indices
\end{tabular}

Table 2. Summaries of 5 different temperature (Temp, ${ }^{\circ} \mathrm{C}$ ) treatments and delay times (min) between death and preservation in average defatted dry weight (DDW, $\mu \mathrm{g}$ ), triacylglycerol (TAG), sterols (ST), phospholipids (PL), diacylglycerols (DAG), monoacylglycerol (MAG), and free fatty acids (FFA) of cod larvae. All lipid measures are expressed in $\mu g$ larva ${ }^{-1}$. All analyses were performed on individual larvae and sample sizes ranged from 25 to 40 individuals per treatment combination (standard deviations in parentheses)

\begin{tabular}{|c|c|c|c|c|c|c|c|c|}
\hline Temp & Time & DDW & TAG & $\mathrm{ST}$ & PL & $D A G$ & MAG & FFA \\
\hline \multirow[t]{6}{*}{3} & 0 & $23.9^{\circ}(3.6)$ & $0.04(0.10)$ & $1.11(0.21)$ & $3.48(1.93)$ & $0.01(0.02)$ & $0.01(0.03)$ & $0.11(0.33)$ \\
\hline & 20 & $26.3(3.3)$ & $0.17(0.15)$ & $0.75(0.37)$ & $10.81(2.50)$ & $0.01(0.02)$ & $0.04(0.15)$ & $0.20(0.16)$ \\
\hline & 35 & $25.2(4.3)$ & $0.11(0.14)$ & $0.99(0.28)$ & $6.93(3.52)$ & $0.01(0.01)$ & $0.01(0.01)$ & $0.17(0.17)$ \\
\hline & 80 & $23.9(4.1)$ & $0.09(0.16)$ & $0.79(0.67)$ & $10.32(2.87)$ & $0.07(0.37)$ & $005(0.22)$ & $0.08(0.16)$ \\
\hline & 140 & $26.9(2.4)$ & $0.14(0.16)$ & $1.01(0.20)$ & $9.51(2.12)$ & $0.03(0.08)$ & $0.06(0.08)$ & $0.14(0.07)$ \\
\hline & 200 & $26.1(3.8)$ & $0.13(0.13)$ & $0.95(0.31)$ & $9.11(3.25)$ & $0-$ & $0.05(0.07)$ & $0.25(0.25)$ \\
\hline \multirow[t]{4}{*}{5} & 35 & $21.1^{\mathrm{b}}(5.5)$ & $0.04(0.02)$ & $0.92(0.23)$ & $5.34(2.66)$ & $0.02(0.03)$ & $0-$ & $0.04(0.04)$ \\
\hline & 80 & $26.3(2.3)$ & $0.09(0.11)$ & $0.80(0.26)$ & $10.07(4.27)$ & $0.01(0.02)$ & $0.08(0.07)$ & $0.14(0.17)$ \\
\hline & 140 & $25.4(3.7)$ & $0.07(0.08)$ & $0.84(0.20)$ & $7.92(2.37)$ & $0.04(0.06)$ & $0.02(0.04)$ & $0.15(0.12)$ \\
\hline & 200 & $25.9(3.0)$ & $0.11(0.19)$ & $0.99(0.38)$ & $5.86(4.08)$ & $0-$ & $0.01(0.03)$ & $0.49(0.89)$ \\
\hline \multirow[t]{4}{*}{10} & 35 & $24.6(2.8)$ & $0.18(0.22)$ & $1.01(0.14)$ & $7.94(2.09)$ & $0-$ & $0.02(0.03)$ & $0.34(0.39)$ \\
\hline & 80 & $23.9(5.3)$ & $0.09(0.07)$ & $0.87(0.13)$ & $7.02(3.00)$ & $0.02(0.04)$ & & $0.14(0.05)$ \\
\hline & 140 & $25.4(3.6)$ & $0.11(0.13)$ & $1.07(0.35)$ & $5.03(3.31)$ & $0.09(0.32)$ & $0.03(0.15)$ & $0.29(0.27)$ \\
\hline & 200 & $25.8(3.3)$ & $0.09(0.1 .2)$ & $0.99(0.21)$ & $6.47(3.65)$ & $0.03(0.14)$ & $0.06(0.05)$ & $0.93(0.94)$ \\
\hline \multirow[t]{4}{*}{15} & 35 & $25.1(3.4)$ & $0.02(0.03)$ & $0.83(0.21)$ & $9.37(1.95)$ & $0.04(0.08)$ & $0.08(0.06)$ & $0.18(0.09)$ \\
\hline & 80 & $26.0(3.0)$ & $0.08(0.07)$ & $0.99(0.34)$ & $8.32(5.14)$ & $0.02(0.06)$ & $0.04(0.05)$ & $0.14(0.11)$ \\
\hline & 140 & $25.8(4.3)$ & $0.10(0.11)$ & $0.94(0.19)$ & $9.12(2.73)$ & $0.16(0.24)$ & $0.04(0.05)$ & $0.31(0.12)$ \\
\hline & 200 & $27.4(3.5)$ & $0.21(0.21)$ & $0.76(0.25)$ & $8.46(3.51)$ & $0.18(0.15)$ & $0.03(0.06)$ & $0.29(0.36)$ \\
\hline \multirow[t]{4}{*}{21} & 35 & $25.9(1.7)$ & $0.08(0.06)$ & $0.86(0.23)$ & $7.48(5.61)$ & $0.01(0.01)$ & $0.05(0.08)$ & $0.15(0.10)$ \\
\hline & 80 & $23.8(4.7)$ & $0.06(0.05)$ & $0.96(0.34)$ & $5.70(4.66)$ & $0.02(0.02)$ & $0.02(0.03)$ & $0.21(0.15)$ \\
\hline & 140 & $23.2(5.8)$ & $0.03(0.07)$ & $0.74(0.40)$ & $9.00(3.40)$ & $0.07(0.09)$ & $0.06(0.05)$ & $0.14(0.13)$ \\
\hline & 200 & $24.2(5.4)$ & $0.07(0.12)$ & $0.90(0.29)$ & $9.72(2.38)$ & $0.05(0.14)$ & $0.16(0.31)$ & $0.23(0.14)$ \\
\hline
\end{tabular}

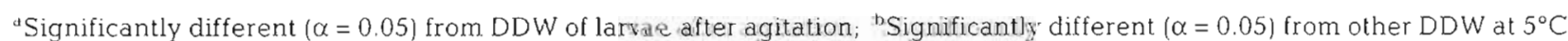


Table 3. Analyses of covariance for $\log _{10}$ and rank transformed triacylglycerols (TAG), sterols (ST), phospholipids (PL), diacylglycerols (DAG), monoacylglycerols (MAG), and free fatty acids (FFA) among larvae collected live and larvae agitated in a mesh container for $20 \mathrm{~min}$. Transformed defatted dry weight (DDW) was used as the covariate

\begin{tabular}{|llcc|}
\hline $\begin{array}{l}\text { Lipid } \\
\text { class }\end{array}$ & $\begin{array}{c}\text { Source of } \\
\text { variability }\end{array}$ & $\begin{array}{c}\text { Log }_{10} \text { trans- } \\
\text { formation } \\
\text { p-value }\end{array}$ & $\begin{array}{c}\text { Rank trans- } \\
\text { formation } \\
\text { p-value }\end{array}$ \\
\hline TAG & Time & 0.001 & 0.001 \\
ST & DDW & 0.522 & 0.975 \\
& Time & 0.001 & 0.001 \\
PL & DDW & 0.090 & 0.129 \\
DAG & Time & 0.001 & 0.001 \\
& DDW & 0.241 & 0.951 \\
MAG & Time & 0.080 & 0.004 \\
FFA & DDW & 0.946 & 0.691 \\
& Time & 0.055 & 0.457 \\
& DDW & 0.256 & 0.416 \\
& Time & 0.001 & 0.002 \\
\hline
\end{tabular}

Analyses of covariance on $\log _{10}$ transformed data showed significantly more TAG, PL, and FFA and significantly less ST in larvae subjected to a simulated sampling protocol than larvae collected live and immediately preserved (Table 3 ). The same analyses performed on rank transformed data gave consistent results, except that significantly more DAG was detected in larvae that were subjected to simulated sampling relative to larvae collected live and preserved immediately.

We regressed each lipid class against time, using DDW as an additional source of variation, for each temperature treatment to examine the effect of time delays between death and preservation. Where TAG decreased $(\alpha=0.05)$ with time at 5,10 , and $21^{\circ} \mathrm{C}$ (Table 4), both DAG and MAG increased with time, but not at all temperatures. Phospholipids decreased while FFA increased with time at 5,10 , and $15^{\circ} \mathrm{C}$. However, the proportion of the total variation explained by any of the significant regressions ranged from only 2 to $32 \%$, at best (Table 4). These results indicate that the effect of temperature on lipid degradation is minimal, and is not systematic. A striking example is that the lipid class composition of larvae held at the lowest and highest temperatures did not differ significantly at most time delays (Fig. 2).

\section{DISCUSSION}

Our work showed that the influence of post-mortem alteration of lipid class composition during a 1 to $3 \mathrm{~h}$ time period after death prior to preservation was small. However, the influence of prey items in the guts of cod larvae was large and could severely bias lipid-based condition indices. These factors could affect the decision to use lipid class composition as a measure of condition rather than other available condition measures.

A number of approaches can be used to evaluate the condition of larval fish and invertebrates. These methods include gravimetric and morphometric characteristics of the whole individual, the appearance and arrangement of cells among different tissues (histological measures), and the dynamics of cellular state and rate indicators and energy substrates (biochemical measures). Current techniques focus on biochemical (Hakanson 1989, Lochmann et al. 1995), physiological (Pedersen et al. 1987, Ueberschär \& Clemmesen 1992), histological and histochemical $\left(O^{\prime}\right.$ Connell \& Paloma 1981, Theilacker \& Watanabe 1989) measures of individuals. Each of these measures has advantages and limitations, and the suitability of any condition measure depends upon the abjectives of the particular study. Regardless of the measure, investigators must

Table 4. Results of regression analyses of $\log _{10}$ and rank transformed triacylglycerol (TAG), sterols (ST), phospholipids (PL), diacylglycerols (DAG), monoacylglycerols (MAG), and free fatty acids (FFA) against time (after agitation in the mesh container and prior to preservation and $\log _{10}$ or rank transformed DDW for different temperatures. Only instances where at least one of the transformations yielded significant regressions against time at the $\alpha=0.05$ level are listed

\begin{tabular}{|c|c|c|c|c|c|}
\hline \multirow[t]{2}{*}{$\begin{array}{l}\text { Temp. } \\
\left({ }^{\circ} \mathrm{C}\right)\end{array}$} & \multirow{2}{*}{$\begin{array}{c}\text { Sign } \\
\text { of time } \\
\text { parameter }\end{array}$} & \multicolumn{2}{|c|}{$\begin{array}{l}\log _{10} \\
\text { transformed }\end{array}$} & \multicolumn{2}{|c|}{$\begin{array}{c}\text { Rank } \\
\text { transformed }\end{array}$} \\
\hline & & $r^{2}$ & p-value & $r^{2}$ & $p$-value \\
\hline \multicolumn{6}{|l|}{ TAG } \\
\hline 5 & - & 0.07 & 0.029 & 0.07 & 0.011 \\
\hline 10 & - & 0.13 & 0.002 & 0.11 & 0.007 \\
\hline 21 & - & 0.19 & 0.001 & 0.21 & 0.001 \\
\hline \multicolumn{6}{|l|}{ ST } \\
\hline 5 & + & 0.02 & 0.158 & 0.05 & 0.006 \\
\hline 10 & + & 0.06 & 0.006 & 0.10 & 0.001 \\
\hline \multicolumn{6}{|l|}{ PL } \\
\hline 5 & - & 0.13 & 0.001 & 0.14 & 0.001 \\
\hline 10 & - & 0.32 & 0.001 & 0.29 & 0.001 \\
\hline 15 & - & 0.05 & 0.019 & 0.04 & 0.006 \\
\hline \multicolumn{6}{|l|}{ DAG } \\
\hline 15 & + & 0.27 & 0.001 & 0.27 & 0.001 \\
\hline 21 & + & 0.08 & 0.002 & 0.03 & 0.117 \\
\hline \multicolumn{6}{|l|}{ MAG } \\
\hline 3 & + & 0.06 & 0.001 & 0.07 & 0.001 \\
\hline 10 & + & 0.05 & 0.014 & 0.09 & 0.001 \\
\hline 21 & + & 0.10 & 0.001 & 0.10 & 0.001 \\
\hline \multicolumn{6}{|l|}{ FFA } \\
\hline 5 & + & 0.06 & 0.004 & 0.05 & 0.041 \\
\hline 10 & + & 0.18 & 0.001 & 0.13 & 0.001 \\
\hline 15 & + & 0.06 & 0.003 & 0.05 & 0.007 \\
\hline
\end{tabular}



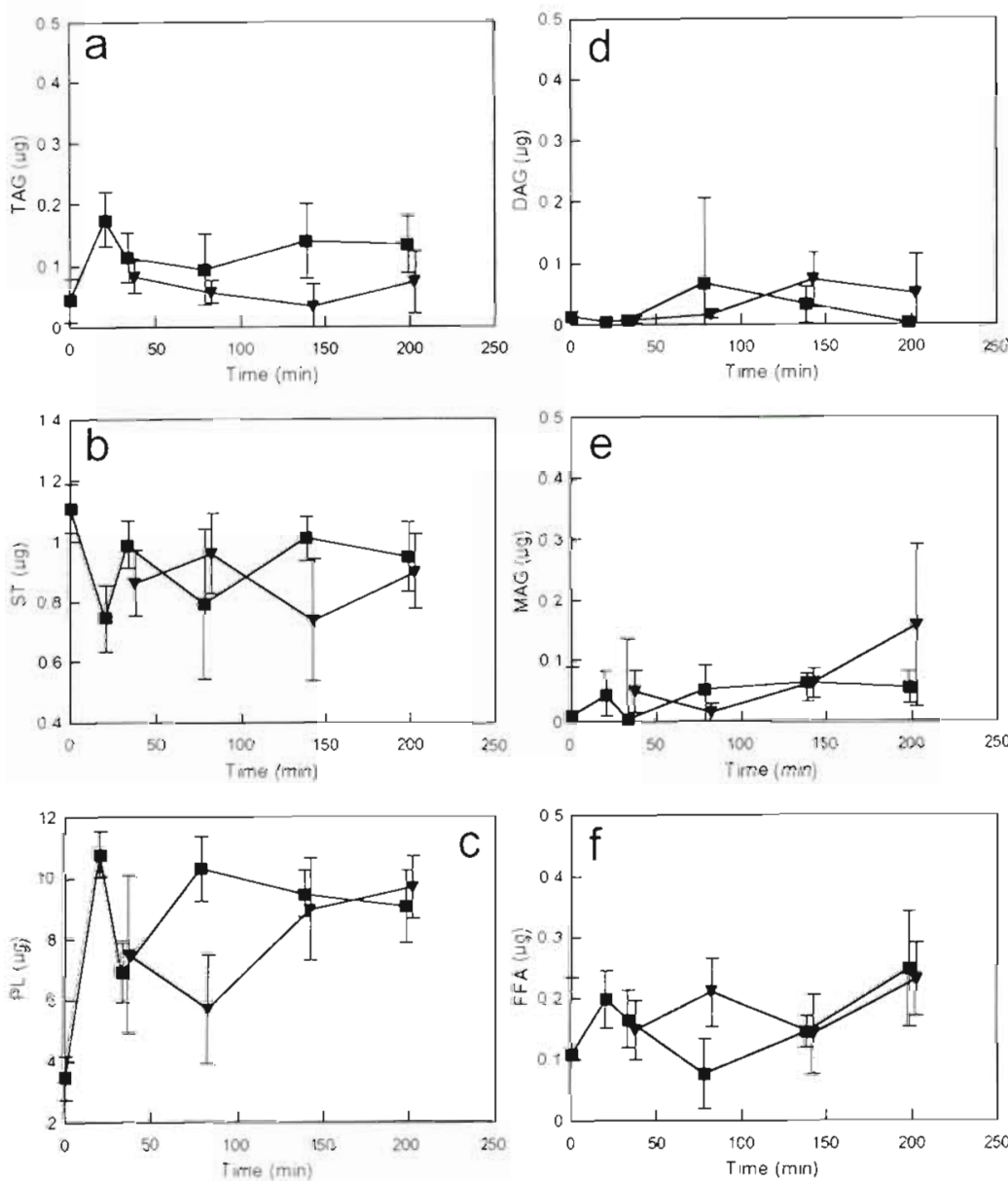

Fig. 2. Measures of individual lipid classes as a function of time delay at 2 different holding temperatures. Average $( \pm 2 \mathrm{SE}$ ) (a) triacylglycerols (TAG); (b) sterols (ST); (c) polar or phospholipids (PL); (d) diacylglycerols (DAG); (e) monoacylglycerols (MAG); and (f) free fatty acids (FFA) for larval cod at $3^{\circ} \mathrm{C}(\mathbf{\square})$ and $21^{\circ} \mathrm{C}(\mathbf{v})$. Larvae were collected live $(t=0)$ and after being subjected to simulated sampling in a mesh container $(t=20)$ at $3^{\circ} \mathrm{C}$, and at several time delays after simulated sampling and prior to preservation. Data presentation at fixed intervals have been slightly offset to allow comparison of standard errors Sample sizes ranged from 28 to 40 Iarvae

ensure that proper calibration occurs and appropriate sampling protocols are followed when assessing the condition of individual animals.

Most published studies indicate that biochemical measures serve as a suitable proxy of physiological condition. However, factors other than nutrition, which are often overlooked, may contribute significantly to variability and influence the interpretation of the biochemical measures (see Ferron \& Leggett 1994 and references therein). Although biochemical measures may provide more sensitive indices to assess condition relative to morphometric and gravimetric measures, they may also be more susceptible to biases that result from differential sample collection and processing protocols.
Contamination of biochemical measures by ingested prey is one source of variability. The inclusion of gut contents in analyses of lipid composition implicitly assumes that all of the lipids in the gut would have been assimilated, or that the contribution of lipids from gut contents is minimal. Assimilation is neither completely efficient nor constant (Boehlert \& Yoklavich 1984). Our results show that the lipids from prey in the guts contributed significantly to all lipid classes present in the tissues of Atlantic cod larvae

Structural lipid classes such as ST have been used as a proxy for body size (Fraser 1989, Hakanson 1989). Our study showed that ST from the gut and its contents can represent up to $96 \%$ of the total ST in an individual cod larva. Triacylglycerol concentration is a measure of the amount of energy reserves in larval fish. However, inclusion of gut contents in lipid analysis can result in a 5- to 20 -fold overestimate of this lipid class. Thus, the TAG:ST ratio can be dramatically affected by the inclusion of lipids from gut contents. In general, differences between TAG:ST ratios calculated with and without lipids from gut contents were on the order of 10 to $20 \%$ (Fig. 3a). In one instance, the TAG:ST ratios (gut contents included or excluded) were equal (fish 9), but for another individual (fish 5), the ratios differed by a factor of $150 \%$. The TAG:ST ratio calculated with lipids from gut contents can easily overestimate or underestimate the TAG:ST ratio based on lipids from tissue alone, the nature of the bias being dependent upon the recent feeding success and upon the lipid class composition of the prey items. These factors would thus confound any comparative analyses among fish larvae unless prey items are removed prior to lipid analysis.

Other biochemical measures (e.g. nucleic acids, proteins, amino acids) are likely to be influenced by the addition of constituents from the prey items and such influences should be evaluated. Evidence of diel feeding periodicity and diel fluctuations in biochemical measures in marine fish larvae indicate the necessity for evaluation (Ferron 1991, Mugiya \& Oka 1991. McLaren \& Avendano 1995). We found the extent to which most investigators addressed this source of vari- 


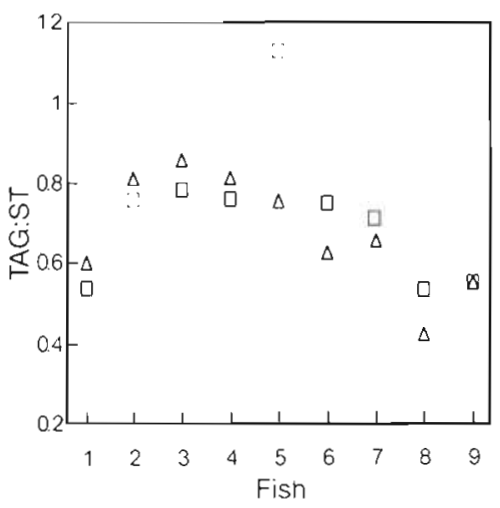

Fig. 3. Companson of triacylglycerol to sterol ratio (TAG:ST) with lipids from gut contents included $(\Delta)$ and excluded $(\square)$ for 9 cod larvae representative of the 20 larvae for which guts and carcasses were analysed separately

ability in previous studies to be surprisingly low. Only $25 \%$ of the studies we examined addressed the potential influence of prey content on biochemical measures of condition. The remaining $75 \%$ implicitly assumed no significant effect of gut contents on condition measures. We recommend that gut contents be removed prior to biochemical analyses. However, our technique for removal of gut contents was to entirely remove the gut. In early stage marine fish larvae with incompletely developed digestive systems, some temporary lipid storage may occur in the foregut (Kjørsvik et al. 1991). In order to quantify all the lipids that have been assimilated by individual larvae, we fur ther recommend that gut contents be removed, but that the gut itself be andlyzed with the carcass.

Post-mortem alteration of biochemical constituents prior to preservation due to the release of enzymatic substances and to oxidation is a source of variability in biochemical measures of condition. In such analyses, it is important that preservation of the material is done quickly to minimize the enzymatic and oxidative processes that can begin immediately after death and which are slowed, but not necessarily stopped, at freezing temperatures (Nishimoto et al. 1977, Sasaki \& Capuzzo 1984, Tocher et al. 1985). This is an important consideration for field surveys where collection of specimens, sorting, and preservation may require significant variations in temperature and processing delays. The new technology of multiple net sampling systems allows the resolution of larval characteristics at small spatial scales. However, if each net of a 10 net system is deployed for $5 \mathrm{~min}$, there is a potential difference between death and preservation on the order of 50 min between larvae collected in the first and last nets. Comparisons of biochemical measures of larvae from different nets could not only be biased, but biased in a spatially systematic manner.
The lipid compositions of larvae sampled before and after agitation in a mesh container (simulating the effect of net sampling) were different. However, the changes we observed were not as expected. We had anticipated that complex lipid classes such as TAG and PL would decrease and lipid classes which have been suggested to be symptomatic of degradation (DAG, MAG, and FFA) would increase (Christie 1973, Fraser 1989). Although FFA increased significantly, so did TAG and PL. Lipid content is size-dependent and larvae randomly sampled from the mesh container after agitation were larger than larvae collected alive. We do not suggest that agitation caused the increase in DDW and analyses of covariance was used to account for the size differences. It appears that there is no simple explanation for these lipid differences. The lipid composition of larvae collected live, though different from larvae after agitation, was not dissimilar to the lipid composition of larvae collected at other times and temperatures (Table 2; Fig. 2). As the results did not show systematic degradation of complex lipids, wè are not overly concerned that collection in net samplers dramatically altered the lipid class composition of larval cod. Furthermore, it is unlikely that field collections with other types of samplers, such as a pump, would be of greater advantage in collecting larvae closer to their live state. We conclude that differences due to agitation in plankton nets are relatively small and unavoidable.

We had also expected that complex lipids would decrease and that the degradation products would increase with the delay time between death and preservation. Time trends for TAG and PL, when significant, were negative (Table 4) and time trends for DAG, MAG, and FFA, when significant, were positive. There is evidence that the degradation of complex lipid classes resulted in accumulation of products symptomatic of degradation. However, the time trend accounted for a small portion of the observed variability. The amount of variability in TAG explained by time between death and preservation ranged from 7 to $21 \%$ (Table 4). The time trends in PL and FFA only explained between 4 and $32 \%$ of the variability in those lipid classes.

The time trend explained more of the variability in TAG content as temperature increased. The same was not true of PL and FFA, where the time trend explained the greatest amount of variability at $10^{\circ} \mathrm{C}$. The time trend explained less than $10 \%$ of the variability in ST at every temperature. Possibly, the enzymes responsible for degradation of TAG and PL do not have the same optimal temperature ranges for activity. We recommend minimizing the time between death and preservation and suggest that sample sorting or processing prior to preservation for biochemical analyses be done at temperatures approaching zero. However, 
our results suggest that time delays on the order of 2 to $3 \mathrm{~h}$ contribute a small portion to the overall variability one might expect to observe in some of the more complex lipid classes. The presence of DAG, MAG, and FFA have been observed in fish larvae collected live and preserved immediately in liquid nitrogen (Tocher et al. 1985, this study). We suggest that the presence of DAG, MAG, and FFA may not necessarily indicate significant degradation of more complex lipid classes and may reflect a suspended state of the dynamics of lipid biochemistry.

Although our study focused on lipid content, our findings may be relevant to other biochemically based measures potentially affected by post-mortem alterations. We observed some evidence of post-mortem degredation of lipids after 2 to $3 \mathrm{~h}$. However, the work of Ferguson \& Drahushchak (1989) showed little enzymatic breakdown of RNA and DNA even when $24 \mathrm{~h}$ elapsed between death and preservation. It would be useful to examine the potential for post-mortem alterations in all biochemical constituents used as condition indicators in larval fish. This would help with decisions regarding appropriate condition measures given specific sampling protocol constraints. To our knowledge, no other study compares a biochemical measure from the gut and its contents to the larval carcass. Prey items in the guts of larval fish can influence absolute measures (e.g. TAG concentration) and indices based on ratios of chemical constituents (e.g. TAG:ST and RNA:DNA ratios). The magnitude of the influence of prey items in the guts on biochemically based condition measures may vary from index to index and we recommend that this influence be quantified for other condition indices. The sources of variability, other than nutrition, in biochemically based condition indices could explain apparent disagreements over population health based on different methods (Seltzer-Hamilton et al. 1987) and must be addressed before assessment of condition of populations of larval fish will become useful as a management tool.

Acknowledgements. We thank Dr S. McClatchie for his valuable contribution to this work and Dr J. Brown for providing fertilized Atlantic cod eggs. P. Simard and K. McNulty provided technical assistance. We thank 3 anonymous reviewers for their constructive criticisms. This research was supported by the Ocean Production Enhancement Network (OPEN), one of the 15 Networks of Centres of Excellence supported by the Government of Canada from 1990 to 1994, designed to pursue collaborative research in a strategic area of national importance. OPEN's research focused primarily on fisheries oceanography.

\section{LITERATURE CITED}

Ackman RG, McLeod CA, Banerjee AK (1990) An overview of analyses by Chromarod-Iatroscan TLC-FID. J Planar Chromatogr 3:450-490
Boehlert GW, Yoklavich MM (1984) Carbon assimilation as a function of ingestion rate in larval Pacific herring. Clupea harengus pallasi Valenciennes. J Exp Mar Biol Ecol 79: $251-262$

Buckley LJ (1979) Relationship between RNA/DNA ratio, prey density and growth rate in Atlantic cod (Gadus morhual larvae. J Fish Res Bd Can 36:1497-1502

Buckley LJ (1980) Changes in the ribonucleic acid, deoxyribonucleic acid, and protein content during ontogenesis in winter flounder, Pseudopleuronectes americanus, and the effect of starvation. Fish Bull US 77:703-708

Buckley LJ (1984) RNA-DNA ratio: an index of larval fish growth in the sea. Mar Biol 80:291-298

Bulow FJ (1970) RNA-DNA ratios as indicators of recent growth rates of a fish. J Fish Res Bd Can 27:2343-2349

Christie WW (1973) Lipid analysis. Pergamon Press, Oxford

Clarke ME, Calvi C, Domeier $M$, Edmonds $M$, Walsh PJ (1992) Effect of nutrition and temperature on metabolic enzyme activities in larval and juvenile red drum, Sciaenops ocellatus, and lane snapper, Lutjanus synagris Mar Biol 112:31-36

Clemmesen C (1987) Laboratory studies on RNA/DNA ratios of starved and fed herring (Clupea harengus) and turbot (Scophthalmus maximus) larvae. J Cons Int Explor Mer 43: $122-128$

Ferguson MM, Drahushchak LR (1989) Effects of tissue collection and storage methods on nucleic acid determinations in white muscle of fishes. Trans Am Fish Soc 118:709-713

Ferron A (1991) État nutritionnel des larves de maquereau Scomber scombrus en rapport avec la disponibilité de nourriture et la structure physique côtiere dans le sudouest du Golfe: Saint-Laurent. MSc thesis, Université du Quebec

Ferron A, Leggett WC (1994) An appraisal of condition measures for marine fish larvae. Adv Mar Biol 30:217-303

Fraser AJ (1989) Triacylglycerol content as a condition index for fish, bivalve, and crustacean larvae. Can J Fish Aquat Sci 46A:1868-1873

Gallager SM, Mann R, Sasaki GC (1986) Lipid as an index of growth and viability in three species of bivalve larvae. Aquaculture 56:81-103

Griffin D, Anderson C (1993) Meteorological, hydrographic. and acoustic doppler current profiler (ADCP) observations on the Scotian Shelf. OPEN Report 1993/4, Dalhousie University, Halifax

Hakanson JL (1987) The feeding condition of Calanus pacificus and other zooplankton in relation to phytoplankton pigments in the Californa Current. Limnol Oceanogr 32 $881-894$

Hakanson JL (1989) Analysis of lipid components for determining the condition of anchovy larvae, Engraulis mordax. Mar Biol 102:143-151

Hakanson JL (1993) Nutritional condition and growth rate of anchovy larvae (Engraulis mordax) in the California Current: two contrasting years. Mar Biol 115:309-316

Hjelmeland K, Huse I, Jorgensen T, Molovik G, Raae J (1984) Trypsin and trypsinogen as indices of growth and survival potential of cod Gadus morhua larvae. In: Dahl $E_{\text {, }}$ Danielssen DS, Moksness E, Solemdal P (eds) The propagation of cod Gadus morhua, L. Flødevigen Rapportser 1. 1984. Institute of Marine Research, Flødevigen Biological Station, Arendal, Norway, p 189-202

Kjrsvik E, van der Meeren T. Kryvi H, Arnfinnson J, Kvenseth PG (1991) Early development of the digestive tract of cod larvae, Gadus morhua L., during start-feeding and starvation. J Fish Biol 38:1-15

Lochmann SE, Maillet GL, Frank KT, Taggart CT (1995) Lipid 
class composition as a measure of nutritional condition in individual larval Atlantic cod Gadus morhua. Can J Fish Aquat Sci 52:1294-1306

McLaren IA, Avendano P (1995) Prey field and diet of larval cod on western bank, Scotian Shelf. Can J Fish Aquat Sci $52: 448-463$

Mugiya Y, Oka H (1991) Biochemical relationship between otolith and somatic growth in the rainbow trout Oncorbyn. chus mykiss: consequence of starvation, resumed feeding and diel variations. Fish Bull US 89:39-245

Nishimoto J, Harada R, Miki J (1977) Studies on lipid in the muscle of skipjack (Katsuwonus pelamis) II. Deterioration pattern of major lipid classes in the muscle stored at $0^{\circ} \mathrm{C}$. Mem Fac Fish Kagoshima Univ 26:119-128

O'Connell CP, Paloma PA (1981) Histochemical indications of liver glycogen in samples of emaciated and robust larvae of the northern anchovy Engraulis mordax. Fish Bull US $79: 806-812$

Ouellet P, Taggary CT, Frank KT (1992) Lipid condition and survival in shrimp (Pandalus borelis) larvae. Can J Fish Aquat Sci 49:368-378

Pedersen BH, Nilssen EM, Hjelmeland K (1987) Variations in the content of trypson and trypsinogen in larval herring Clupea harengus digesting copepod nauplii. Mar Biol 94: $171-181$

This article was submitted to the editor
Sasaki GC, Capuzzo JM (1984) Degradation of Artemia lipids under storage. Comp Blochem Physiol 78B:525-531

Seltzer-Hamilton EM, Wrught DA, Martin FD, Millsaps CV, Whitlow SI (1987) Analysis of nutritional condition and its use in predicting striped bass recruitment: field studies. Am Fish Soc Symp 2:115-128

Shearer KD (1994) Factors affecting the proximate composition of cultured fishes with emphasis on salmonids. Aquaculture 119:63-88

Theilacker GH, Watanabe Y (1989) Midgut cell height defines nutritional status of laboratory raised larval northern anchovy Engrauls mordax. Fish Bull US 87:457-469

Tocher DR, Fraser AJ, Sargent JR, Gamble JC (1985) Lipid class composition during embryonic and early larval development in Atlantic herring (Clupea harengus, L.). Lipids 20:84-89

Ueberschär B (1988) Determination of the nutritional condition of individual marine fish larvae by analyzing their proteolytic enzyme activities with a highly sensitive fluoresence technique. Meeresforsch 32:144-154

Ueberschär B, Clemmesen C (1992) A comparison of the nutritional condition of herring larvae as determined by two biochemical methods - tryptic enzyme activity and RNA/DNA ratio measurements. ICES J Mar Sci 49: $245-249$

Manuscript first received: April 10, 1995

Revised version accepted: September 14, 1995 